\title{
Author Correction: Matching consumer segments to innovative utility business models
}

Stephen Hall(1), Jillian Anable, Jeffrey Hardy $\mathbb{D}^{\mathbb{D}}$, Mark Workman, Christoph Mazur and Yvonne Matthews

Correction to: Nature Energy https://doi.org/10.1038/s41560-021-00781-1, published online 1 March 2021.

In the version of this Article originally published, in Fig. 2 the final bar, labelled '3PC', was missing, as was the corresponding data in the Supplementary Data file. The figure has been corrected in all versions of the Article and the Supplementary Data file replaced.

Published online: 12 March 2021

https://doi.org/10.1038/s41560-021-00809-6

(C) The Author(s), under exclusive licence to Springer Nature Limited 2021 